\title{
Case Study of Electron Beam Welding IN AUTOMOTIVE INDUSTRY
}

\author{
Jozef Ertel, Jozef Bárta, Milan Marônek \\ Slovak University of Technology in Bratilsava, Faculty of Materials Science and Technology in Trnava, Institute of \\ Production Technologies Paulínska 16, 91724 Trnava, Slovak Republic
}

\begin{abstract}
The laser and electron beam welding belong to progressive welding methods and their application is rapidly being expanded. The mentioned methods are, as an example, widely applied in an automotive and engineering industry i. e. in mass as well as serial production. The both processes are characteristic by a very short time welding cycle and a small volume of molten weld metal, which results into narrow heat affected zone and lower weld joint deformation. The article in the form of case study describes problem of hot cracking during electron beam welding in an automotive industry and suggests solution.
\end{abstract}

Keywords: electron beam; thermal conductivity; grain shape; production technology, crystallisation cracks
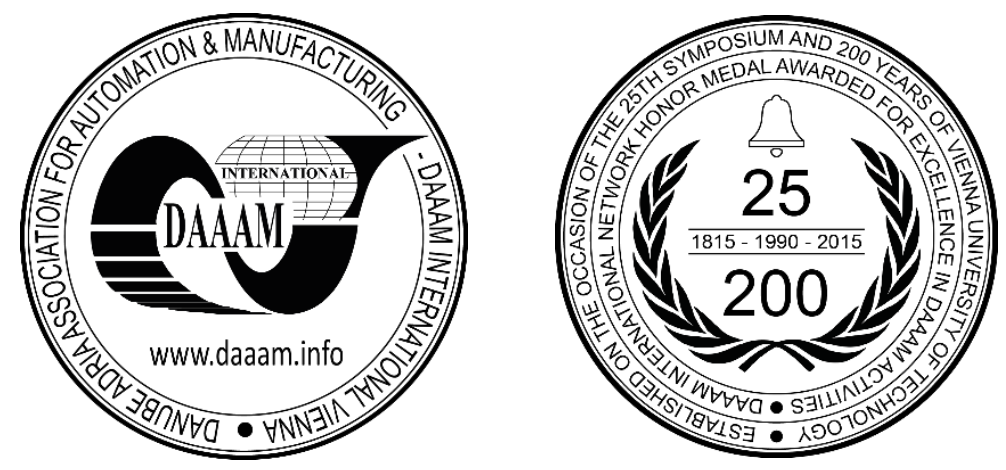

This Publication has to be referred as: Ertel, J[ozef]; Barta, J[ozef] \& Maronek, M[ilan] (2016). Case Study of Electron Beam Welding in Automotive Industry, Proceedings of the 26th DAAAM International Symposium, pp.1138-1142, B. Katalinic (Ed.), Published by DAAAM International, ISBN 978-3-902734-07-5, ISSN 1726-9679, Vienna, Austria DOI: $10.2507 / 26$ th.daaam.proceedings. 160 


\section{Introduction}

The first knowledge about existence of electrons brought Wilhelm Hittorf from Göttingen and William Crook in 1872. Soon Edison discovered the emission of electron radiation. Electron beam melted anticathode what was an inspiration for utilisation of electron beam as a heat source. The biggest limitation for application of electron beam was the vacuum necessity. The geometry of the optical system was improved in 1930 by Nahs Bush. The first electron microscope was developed by AEG, Siemens and others. Von Ardennym as a first used electron beam for drilling (Fig. 1) $[1,2,3,4,5]$.

The welding by electron beam was accidentally invited during X-Ray manipulation by Dr. Jacquesom Andre Stohrom in 1954. Almost in the same time Dr. Steigerwald in Germany created weld joints by beam manipulation in electron microscope. The first official utilisation of electron beam for welding was announced and performed in 1958 in Bettis, Westinghouse on welding device produced by Zeiss Company. South Korea belongs to one of the biggest importers of EBW devices without self-production. [1, 4, 5].
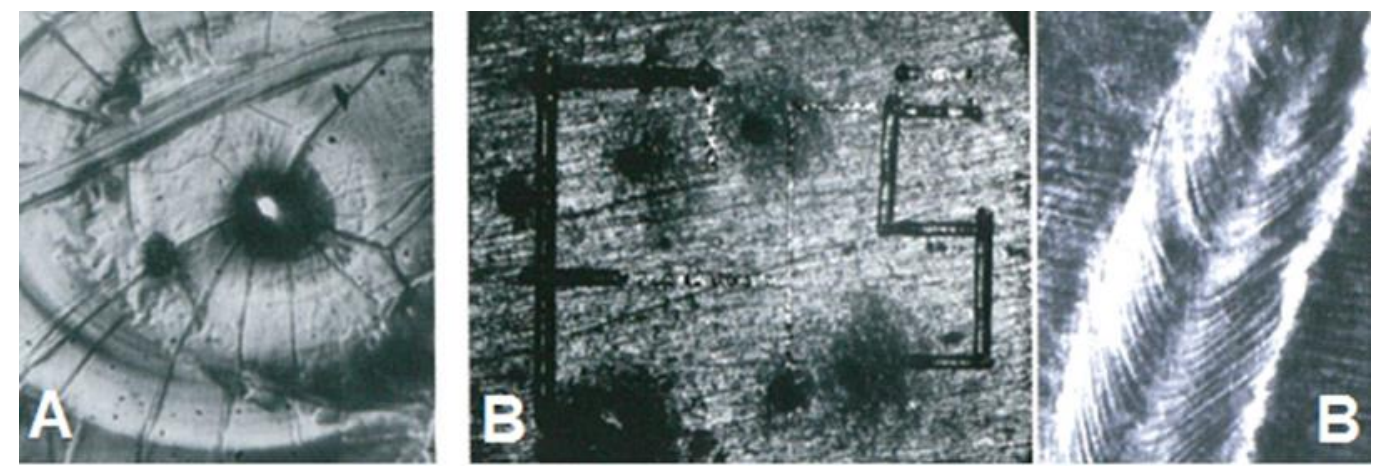

Fig. 1. (A) First EB drilling in platinum 1949, (B) first EB welding 1949 [1]

The development of devices for electron beam welding was influenced by occurrence of various obstacles as well as the use of these devices in an industry. One of the real examples is formation of crystallization cracks in weld metal. Schlett and Bush [8] were dealing with this problem on the weld joints and heat affected zone of the turbine disc because of the sulphur accumulation on the weld surfaces, residual stress and lowered capability of forming of weld joints. There is a direct relationship between the cracks and the amount of sulphur on the grain boundaries in heat affected zone. Goodwin [9] found out, that cracks are forming also by constant value of high heat input or welding speed. By increasing these values the amount of crystallization cracks also increases. Generally, the use of high energy concentrated welding methods produce significantly more cracks than e. g. gas tungsten arc welding. Wopo, Kang and Nishimoto [10] allege, that the use of fine-grained material, or the use of appropriate heat-treatment before welding process can avoid liquation cracks. Kakiuchi at all [11] claim that increase of electron beam welding current increase the amount of cracks on the grain boundaries. These cracks were caused by shrinking of the weld metal during solidification process. Shinji at all [4] discovered that sulphur is the most harmful element in weld metal during the cracks forming process. To eliminate cracking at various positions in weld joints it is necessary to keep the content of the sulphur under 0,002 wt. \% [8, 9, 10, 11]. Nowadays this method is used for example in the aircraft industry to join structural and load bearing elements made of titanium and aluminium alloys, and landing gears made of high strength steel [12]. However, certain problems can arise. For example root spiking or weld porosities [13].

\section{Experiment and results}

Figure 2 documents internal defects in weld joint produced by electron beam welding (Fig. 2).

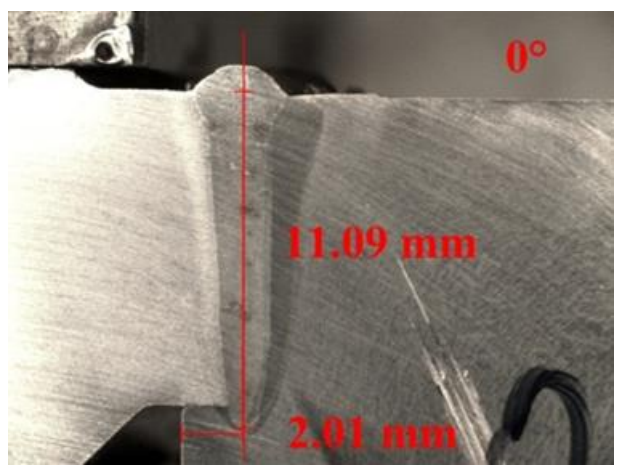

Fig. 2 Weld joint 
Materials welded together were S235JRG2 (0.25 wt. \% C) and MRST4 (0.08 wt. \% C). Chemical composition of both materials is provided in Tab. 1 . The electron beam gun at stationary position generated oscilating electron beam, whereas the rotary table provided the translation movement along the weld joint. The porosity described above was confirmed as hot cracking after detailed SEM analysis (Fig. 3).

\begin{tabular}{|c|c|c|c|c|c|}
\hline \multicolumn{6}{|c|}{ S235JRG2 (1.0038): EN 10250-2-2000 } \\
\hline $\mathrm{C}$ & $\mathrm{Si}$ & $\mathrm{Mn}$ & $\mathrm{Ni}$ & $\mathrm{P}$ & $\mathrm{S}$ \\
\hline $\max \quad 0.2$ & $\max \quad 0.55$ & $\max 1.4$ & $\max \quad 0.3$ & $\max \quad 0.045$ & $\max \quad 0.045$ \\
\hline MR St 4 & & & & & \\
\hline $\mathrm{C}$ & $\mathrm{Si}$ & $\mathrm{Mn}$ & $\mathrm{Ni}$ & $\mathrm{P}$ & $\mathrm{S}$ \\
\hline 0.08 & 0.08 & 0.35 & $\max \quad 0.3$ & 0.035 & 0.035 \\
\hline
\end{tabular}

Table 1. Chemical composition [wt. \%] of steel grades [6, 7]
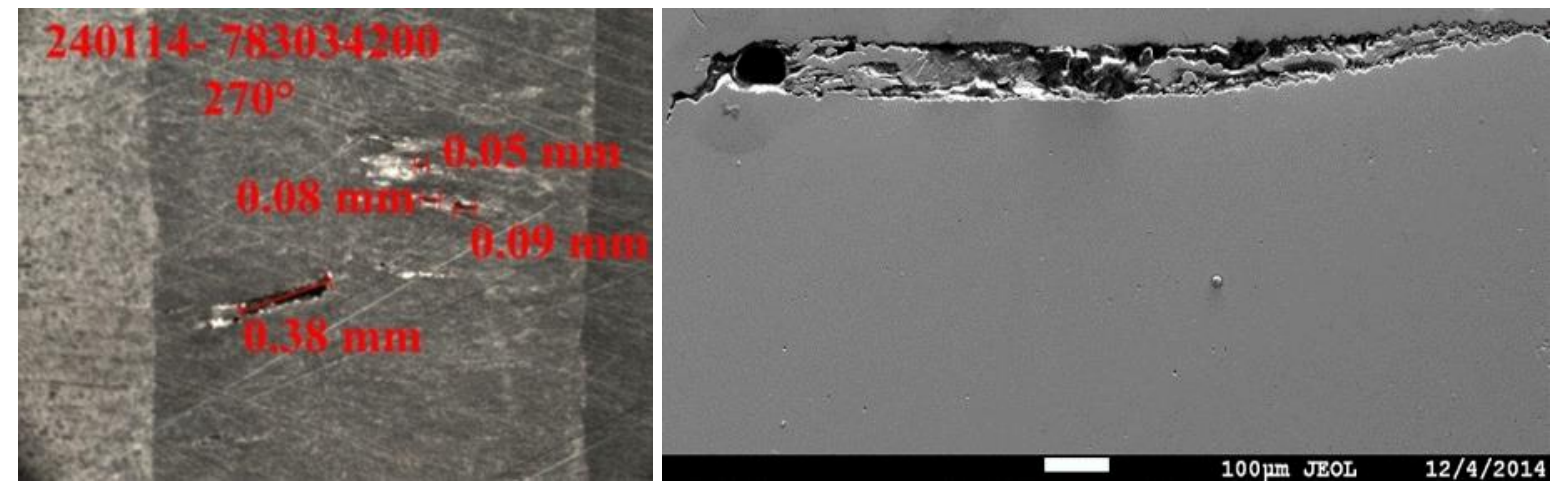

Fig. 3. SEM analysis of hot cracks in the weld metal

Three experiments were proposed to eliminate the hot cracking. The change of electron beam oscillation from linear to rotational was proposed as first. A preheat with linear beam oscillation was the subject of the second experiment. The third experiment came from previous two, where rotational beam oscillation and new welding parameters were applied.

The results of a first experiment proved lower amount of defects but did not eliminated the hot cracking completely. Moreover, impurities were spotted only in the root section of the weld joint (Fig. 4).
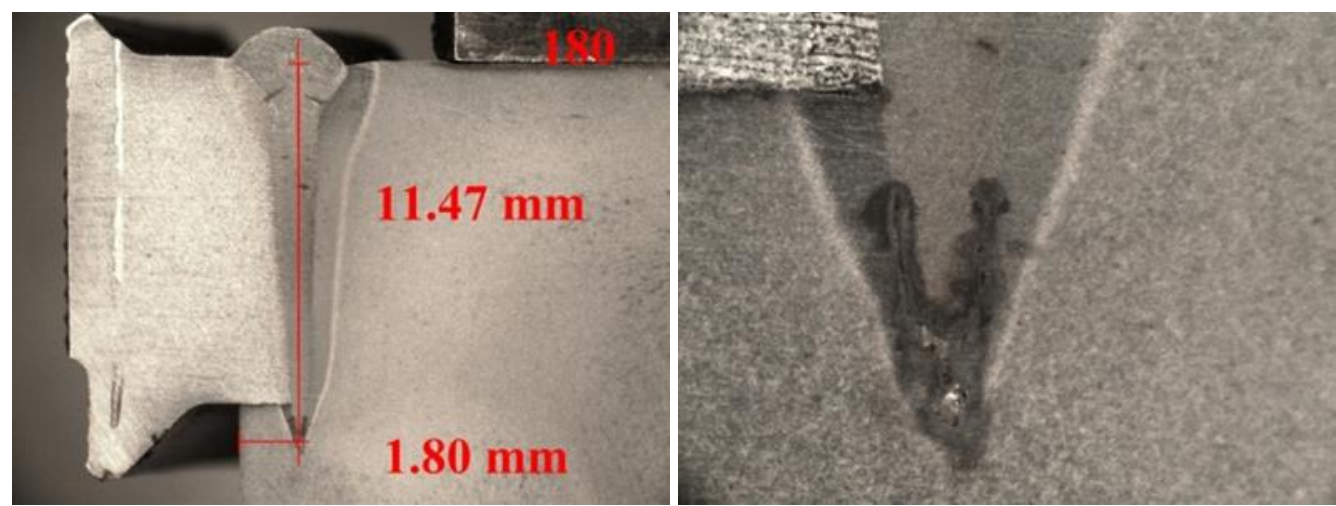

Fig. 4. Weld joint after beam oscillation adjustment.

In the second experiment, a preheat comprising of six transitions over the future joint by defocused beam with half output power. Welding by standard parameters (Tab. 2) using linear beam oscillation perpendicular to welding direction was applied.

\begin{tabular}{lll}
\hline Parameter & Preheat & Welding \\
\hline Welding current $[\mathrm{mA}]$ & 50 & 100 \\
Focusing current $[\mathrm{mA}]$ & 530 & 498 \\
Welding speed $[\mathrm{mm} / \mathrm{s}]$ & 17 & 20 \\
Oscillation frequency [Hz] & 500 & 500 \\
\hline
\end{tabular}

Table 2. Welding parameters used in second experiment 
Consecutive analysis revealed the rapid reduction of hot cracking. However, due to the increased heat input, higher deformation of welded components and massive reinforcement of weld bead was measured (Fig. 5). This approach therefore could not be considered as acceptable since further machining had to be applied after the welding process.

In order to reduce the heat input, the third experiment consisted of preheat with four transitions of defocused electron beam with a half power output. Welding was realised immediately after preheat with parameters provided in Tab. 1. Both, preheat and welding beam oscillation were set to rotational oscillation mode. Final amount of hot cracks was lower in comparison to original state, but higher than results achieved in the second experiment (Fig. 5). On the other hand, the reinforcement of the weld bead as well as the weld joint deformation in this case were lower in comparison to the second experiment.
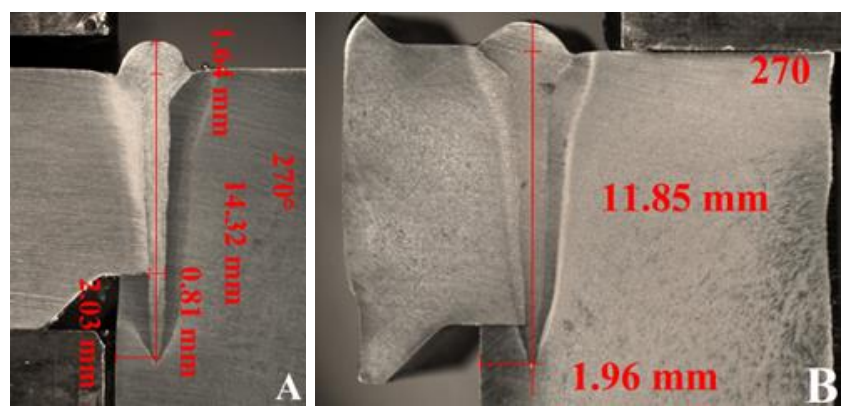

Fig. 5. Macroscopy observation of the weld joints

(A) second experiment

\section{Conclusions}

(B) third experiment

The hot cracking of weld metal was successfully reduced in the third experiment by application of rotational oscillation of electron beam and application of preheat with lower heat input. It is worth mentioning, that the new welding procedure extends manufacturing time, but with regard to small quantity batch production, this change is acceptable. Since the hot cracking was not eliminated completely, further research will be focused on welding parameters adjustment with the emphasis to heat input limitation during the welding phase.

\section{Acknowledgement}

This paper was supported by European Union project "Center for research and development in the field of electron beam and progressive arc welding technologies, surfacing and surface treatment - WeldCenter", ITMS 26210120017 and project Young researchers no. 1346.
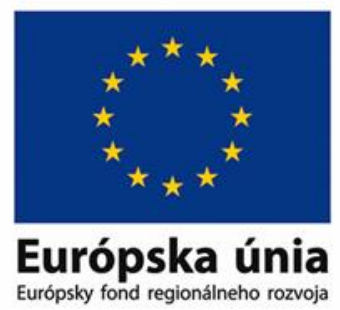

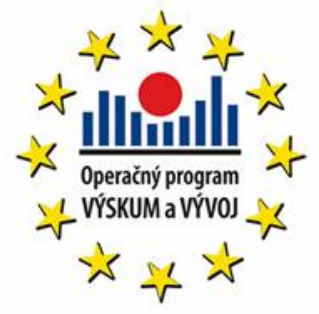

\section{References}

[1] Steigerwald, H. K., Sayegh, G., Powers, D. And Bakish, R., Nazarenko, K. O., Dietrich, W., Irie, H., Wyatt, D. And Dobeneck, V. D.: An International History Of Electron Beam Welding, (02007, Germany: Pro-Beam Ag \&Co

[2] Marônek, M., Bárta, J. R. 2008. Multimediálny sprievodca technológiou zvárania. Welding Technology Multimedia Guide. AlumniPress: STU. ISBN 978-80-8096-066-7

[3] JANOVEC, J., DOMÁNKOVÁ, M., GRGÁČ, P., GÖMÖRY, F., KUSÝ, M. R. 2008 Progresívne materiály a technológie. Progressive Materials and Technologies. AlumniPress: STU. ISBN 978-80-8096-076-6

[4] EB Industries. Electron beam welding. Available online: 〈https://www.ebindustries.com/electron-beam-welding/>, [cit. 2015-01-09]

[5] Schultz Helmut : Electron beam welding, (C1989, Germany: Abington Publishing, ISBN 3-87155-111-2

[6] European Steel and Alloy Grades / Numbers: S235JRG2. Available online: <http://www.steelnumber.com/en/steel_composition_eu.php?name_id=848>, [cit. 2015-30-09]

[7] Ross B. Robert. R 1992. Metallic materials specification handbook. Library of Congress Cataloging in Publication data available. ISBN 978-0-412-36940-7 
[8] V. Schlett V., Busch B. W. R 1995. AES investigations of the hot cracking of an electron-beam welded nickel-base alloy for turbine disks. Fresenius' Journal of analytical chemistry. Available online: < http://link.springer.com/article/10.1007\%2FBF00321319\#page-1>, [cit. 2015-10-13]

[9] Goodwin G. M. R 1988. The Effects of Heat Input and Weld Process on Hot Cracking in Stainless Steel. Welding research supplement. Available online: < https://app.aws.org/wj/supplement/WJ_1988_04_s88.pdf>, [cit. 2015-1013]

[10] Woo I., Kang Ch., Nishimoto K. R 2001. Influence of Electron Beam Welding Parameters and Metallurgical Factors on Intergranular Liquation Cracking Susceptibility of Cast Alloy 718. Materials and materials International, Vol. 7, No. 4 (2001), pp. 349 357. Available online: < http://link.springer.com/article/10.1007\%2FBF03186079\#page-1>, [cit. 2015-10-13]

[11] Kakiuchi S., Tomida S., Yamagishi H. Yoenda T., Nakata K. R 2013. Hot Cracking Phenomena in Electron-beammelted Surface Region of Co-Cr-Mo Alloy. Available online: < http://ci.nii.ac.jp/naid/130004445741>, [cit. 201510-13]

[12] Lacki P., Adamus K., Wieczorek P. 2014. Theoretical and experimental analysis of thermo-mechanical phenomena during electron beam welding process. Computational Materials Science. Available online: <http://www.sciencedirect.com/science/article/pii/S0927025614000330>, [cit. 2015-10-13]

[13] Koleva G. E., Mladenov M. G., Trushnikov N. D., Belenkiy Y. V. 2014, Signal emitted from plasma during electronbeam welding with deflection oscillations of the beam. Journal of Materials Processing Technology. Available online: < http://www.sciencedirect.com/science/article/pii/S0924013614001228>, [cit. 2015-10-13] 